\title{
The social return of academic research
}

A careful economic study reveals that academic research is an excellent investment but the most famous universities may not be the best to invest in.

FOR years, US scientists have justified receiving government support by arguing that whatever investment is made in basic research will eventually be returned many times over in benefits to society. But despite the plausibility of this contention, there has never been any proof until now.

Edwin Mansfield, director of the Center for Economics and Technology at the University of Pennsylvania, has examined the question directly by asking US industry which new products and processes could not have been developed without academic research.

The answer, published earlier this year (in Research Policy 20, 1-12; February 1991) confirms what scientists have said all along: academic research more than pays for itself when its economic contributions to society are taken into account. More recently, however, Mansfield has asked exactly which academic research is most valuable to industry, and these results hold a few surprises. His stillunpublished data show that the most valuable research is not always that done at the best schools or in the large, well-funded research groups. Although he warns that his work is too preliminary to base research policy on, it seems certain to generate discussion and debate over the role and funding of research.

Mansfield chose a random sample of 76 major US companies in seven industries - information processing, electrical equipment, chemicals, instruments, drugs, metals and oil - and asked their executives what percentage of their new products and processes commercialized from 1975 to 1985 could not have been developed (without substantial delay) without academic research carried out in the previous 15 years.

The results were impressive: 11 per cent of the products and 9 per cent of the processes had depended on academic research. The percentages varied from industry to industry, with drugs (27 per cent of products and 29 per cent of processes) at the high end, and oil (1 per cent of each) at the low end.

$\mathrm{He}$ also found that he could put an approximate dollar figure on the value of academic research to industry and to society as a whole. The bottom line, Mansfield calculated, is that investment in academic research has an average annual rate of return to society of about
28 per cent. Although the precise details are complicated by such factors as an average lag time of seven years between research and commercialization, this payback is equivalent in economic terms to putting money into a saving account that annually pays 28 cents on the dollar.

And that is a conservative estimate, says Leonard Lederman of the National Science Foundation, who encouraged Mansfield's work and followed it closely. "He did everything possible to estimate the cost of academic $R \& D$ as high as possible, such as including costs for research that was never intended to have industrial payoffs," Lederman says. "He also estimated low on the return." The result is a rough figure, but one that should, if anything, understate the value of academic research.

Mansfield next went back to the same companies to determine exactly what types of academic research were of greatest worth. He asked each of them to name five researchers whose work during the 1970 s and 1980 s was most valuable to it. Some of the details were predictable, but some were unexpected.

Most predictable were the areas of research of greatest worth to different industries: electronics companies most often cited research done by electrical engineers; information processing companies preferred computer scientists; chemical companies, chemists; and so on. Pharmaceutical companies were the most catholic, pointing to biology, chemistry and pharmacology departments.

Many of the schools producing the most cited research were also predictable: Harvard, the University of California at San Francisco, Stanford and Yale led the list for pharmaceutical companies, and the Massachusetts Institute of Technology and the University of California at Berkeley rated top for both electronics and information processing.

But then there were some surprises. Washington University and the University of Utah were first and third among those cited by the chemical industry, although neither school was in the top 12 on a 1982 list of the country's best chemistry departments compiled by the National Academy of Sciences. The University of Illinois was mentioned more often than Stanford by companies in both electronics and information processing. Intrigued, Mansfield compared industry's rating of university departments with the quality of the faculty as determined by the Academy. He found varying degrees of agreement between the two measures - strongest in electronics, almost nonexistent in chemistry - but on the whole, he says, industry does not seem to favour the most respected departments as much as one might. guess.

Two possible explanations come to mind, Mansfield says. Some otherwise undistinguished departments may have a few very good researchers whose work is valuable to industry. And researchers in the 'better' departments may concentrate on work that has payoffs further than 15 years in the future.

Part of the explanation also seems to be that companies tend to support research at nearby universities, whether or not the schools are highly rated. In turn, the companies are more aware of the research going on at these local universities and more likely to use it in their product development.

Mansfield found that nearly 40 per cent of the researchers cited by electronics and information processing firms worked in the same state as the company that cited them, as did about a quarter of the researchers listed by pharmaceutical and chemical companies. Part of that, Mansfield admits, is due to companies locating near the best research, but even companies that are not close to the best universities find it valuable to support research in nearby, less highly rated schools.

Almost all the individual researchers were funded at least in part by the federal government. Five out of every six also received money from industry to support their research, although industry provided a much smaller average percentage of the funding than government ( 23 per cent against 63 per cent).

More than half of the researchers told Mansfield that the direction of their research had been influenced considerably by the funders, although two-thirds of them insisted that they relied primarily on their own judgement.

Mansfield is cautious about how valuable his studies are for making funding decisions. "It's nice to know that in the past these returns have been considerable," he says, "but these findings alone do not prove anything about the future." The main message, Lederman says, should be that academic research is a good investment.

Robert Pool 